\title{
The Use of PSA Doubling Time to Predict Prognosis and the Use of PSA Response to Assess the Success for Prostate Cancer Patients Undergoing Docetaxel Chemotherapy
}

\author{
Sarp K. Keskin ${ }^{*}$, Asif Yildirim², Cengiz Canakci², Ismail Ulus², Ramazan Gokhan Atis ${ }^{2}$, \\ Turhan Caskurlu² \\ ${ }^{1}$ Department of Urology, The University of Texas MD Anderson Cancer Center, Houston, USA \\ ${ }^{2}$ Department of Urology, The University of Istanbul Medeniyet, Goztepe Training and Research Hospital, \\ Istanbul, Turkey \\ Email: "skkeskin@mdanderson.org
}

Received 27 July 2016; accepted 15 August 2016; published 18 August 2016

Copyright (C) 2016 by authors and Scientific Research Publishing Inc.

This work is licensed under the Creative Commons Attribution International License (CC BY). http://creativecommons.org/licenses/by/4.0/

(c) (i) Open Access

\begin{abstract}
In the targeted therapy era, it is critical to know the certain points to start or discontinue chemotherapy for patients with castration resistant metastatic prostate cancer. The prognostic factors to determine this response are still not clear yet. We tried to find out if the PSA doubling time helps us to predict the patients who will benefit from docetaxel chemotherapy most, and also to question the value of the PSA response to chemotherapy. Retrospectively, 70 patients who had hormone refractory metastatic prostate cancer that were given at least 4 cycles of docetaxel chemotherapy between 2002 and 2015 were evaluated. After the onset of docetaxel, PSA response to therapy and overall survival rates were analyzed to figure out if these parameters were related to PSA doubling time. The only statistically significant prognostic parameter affecting overall survival was the best PSA response rate to docetaxel chemotherapy being over or under $50 \%$. The most significant parameter that affects the PSA doubling time was the clinical stage at the time of diagnosis. PSA doubling time is not a useful predictive tool for predicting response to docetaxel. By means of overall survival, the clinical stage at the time of diagnosis was the best predictive tool for our cohort. The best PSA response rate to docetaxel chemotherapy was found to be a valuable parameter. The study being retrospective and the low number of patients included in this cohort can be the main weaknesses of this study. Further studies to determine which other factors can be useful are needed.
\end{abstract}

\footnotetext{
${ }^{*}$ Corresponding author.
}

How to cite this paper: Keskin, S.K., Yildirim, A., Canakci, C., Ulus, I., Atis, R.G. and Caskurlu, T. (2016) The Use of PSA Doubling Time to Predict Prognosis and the Use of PSA Response to Assess the Success for Prostate Cancer Patients Undergoing Docetaxel Chemotherapy. Journal of Cancer Therapy, 7, 593-599. http://dx.doi.org/10.4236/jct.2016.78062 


\section{Keywords}

\section{Castration Resistant Prostate Cancer, Docetaxel, PSA Doubling Time, PSA Kinetics, Chemotherapy}

\section{Introduction}

Prostate cancer is the most common visceral malignancy amongst men in the US [1]. In addition, it is the most common solid cancer and the most common cause of death due to cancer in European men [2]. Nowadays most of the patients are getting diagnosed as localized prostate cancer [3]. With contemporary treatment options, the overall survival for this group of patients is over 90\% [4] [5]. Men with localised disease can have very different treatment options, ranging from observation alone through to radical surgery, for each individual patient.

For those who have metastatic prostate cancer, the most common first line treatment option is androgen deprivation therapy (ADT). The survival of patients with metastatic prostate cancer progressing on ADT (castrationresistant prostate cancer) has improved substantially. In addition to docetaxel, which has been used for over a decade, new drugs have shown efficacy with improvements in overall survival leading to licensing for the treatment of metastatic castration-resistant prostate cancer (CRPC). Because of these recent changes in the therapeutic landscape, no vigorous data is available to inform on the selection of patients for a specific treatment for CRPC [6] [7]. With the developments in the last decade, we now have many options for hormone refractory metastatic prostate cancer patients like newer generation chemotherapeutics, targeted therapies, vaccines, immune checkpoint inhibitors [8]-[11].

Docetaxel (DX) is one the first cytotoxic therapeutics associated with a survival benefit in CRPC and the most commonly used chemotherapeutic in hormone refractory metastatic prostate cancer patients in the last decade [12]. Because it is an effective therapy, docetaxel is likely to remain an important part of the treatment arsenal against metastatic prostate cancer for the foreseeable future, despite its toxicities and limitations. Every patient represents a unique response to this therapy. In addition, there is no commonly accepted parameter that can be used to predict the response rate or time to chemotherapy. We tried to find out one using the PSA doubling time (PSA-DT).

\section{Materials and Methods}

Seventy patients with castration resistant prostate cancer, who received ADT as first line, and after failure of this therapy, initiated to chemotherapy and received at least 4 cycles of docetaxel at our clinic between 2002 and 2015 were respectively evaluated. Patient characteristics were presented at Table 1.

Table 1. The demographic and clinical findings of patients.

\begin{tabular}{cccccc}
\hline & Number & Minimum & Maximum & Average & Standart Deviation \\
\hline Age & 70 & 52 & 82 & 69.16 & 8.34 \\
Gleason Score & 70 & 4 & 10 & 7.34 & 1.20 \\
Trus-\% & 70 & 40 & 100 & 86.14 & 16.26 \\
Clinical Stage & 70 & 1 & 4 & 2.47 & 0.60 \\
Body Mass Index & 70 & 21 & 30 & 25.19 & 2.42 \\
First PSA (ng/ml) & 70 & 2.86 & 6013 & 317.25 & 948.43 \\
ADT (months) & 70 & 6 & 156 & 42.16 & 31.53 \\
ADT PSA nadir(ng/ml) & 70 & 0.01 & 159 & 6.09 & 21.18 \\
Time to get PSAn with ADT (months) & 70 & 2 & 55 & 13.44 & 10.18 \\
PSA - DT (days) & 70 & 15 & 317 & 83.96 & 57.44 \\
PSA-V (ng/ml/month) & 70 & 0.03 & 310 & 19.31 & 42.07 \\
Last PSA before DX & 70 & 19 & 2499 & 258.82 & 525.96 \\
DX cures & 70 & 4 & 23 & 7.36 & 4.6 \\
Follow Up Time (months) & 70 & 5 & 70 & 22.27 & 13.829 \\
\hline
\end{tabular}


Median time of follow-up was calculated using the reverse Kaplan-Meier method.

The performance status of the patients before chemotherapy was measured by the Eastern Cooperative Oncology Group (ECOG) performance scale [13]. Patients with score 3 and higher were not included.

All the patients received androgen deprivation therapy (ADT) before DX chemotherapy. The PSA-nadir (PSAn) level under ADT was evaluated in two groups $(\leq 4 \mathrm{ng} / \mathrm{ml}$ and $>4 \mathrm{ng} / \mathrm{ml})$.

The PSA-DT was calculated by evaluating all the PSA values between the onset of DX chemotherapy and the PSAn level while receiving ADT. PSA values included were all seen in the last 3 months before the onset of DX chemotherapy.

We used to calculate PSA-DT was the Memorial Sloan Kettering nomograms. To be specific, PSA-DT was calculated by natural log of $2(0.693)$ divided by the slope of the relationship between the log of PSA $\left(\mathrm{P}_{1}, \mathrm{P}_{2}\right)$ and time of PSA $\left(\mathrm{T}_{1}, \mathrm{~T}_{2}\right)$ measurement for each patient. $T=\left(t_{2}-t_{1}\right) \log (2) / \log \left(\mathrm{P}_{2} / \mathrm{P}_{1}\right)[14]$.

The literature evaluation for the PSA-DT showed us that the most used cut-off values were 45 and 70 days [15] [16]. Therefore, we calculated the patients PSA-DT values by using these two cut-off days. We also grouped the patients by their PSA level on diagnosis $(<7 \mathrm{ng} / \mathrm{ml},=7 \mathrm{ng} / \mathrm{ml},>7 \mathrm{ng} / \mathrm{ml})$.

All included patients who had castration resistant prostate cancer (CRPC) had $75 \mathrm{mg} / \mathrm{m}^{2} \mathrm{DX}$ chemotherapy every 21 days. The PSA response to DX was evaluated in three groups (PSA decrease, $<30 \%, 30 \%-50 \%,>50 \%$ )

\section{Statistical Analysis}

Within the cohort, the Cox proportional hazards model was used to model the overall survival. Multiple cause-specific Cox regression models were carried out to associate PSA kinetics. The Cox regression models included age, WHO histopathological grade and either the last PSA before onset of DX PSA or the most recent PSA measurement available. Results are presented as hazard ratios (HRs) with 95\% confidence intervals (CIs).

\section{Results}

Age of the included patients was between 59 and 82 (average, 69). The median Gleason score was 7.34 and the tumor rate at the diagnostic biopsy was $86 \%$. The PSA level at the time of diagnosis was between $2.8 \mathrm{ng} / \mathrm{ml}$ and $6013 \mathrm{ng} / \mathrm{ml}$ (average $317.25 \mathrm{ng} / \mathrm{ml}$ ).

All the patients received ADT before DX chemotherapy. The PSAn level under ADT was evaluated in two groups $(\leq 4 \mathrm{ng} / \mathrm{ml}$ and $>4 \mathrm{ng} / \mathrm{ml}$ ). According to this, $77 \%$ of the patients had PSAn levels under $4 \mathrm{ng} / \mathrm{ml}$. The time to reach the PSAn level was over 6 months in the $87 \%$ of all patients.

Before DX chemotherapy, 28.6\% of the patients had a PSA-DT under 45 days, 21.8\% had PSA-DT between 45 and 70 days, and $48.6 \%$ had a PSA-DT over 70 days. Statistical analysis of these groups showed no significant correlation with survival rates.

We evaluated two possible factors that affect PSA-DT. These were Gleason score and clinical stage at the time of diagnosis. None of these two parameters showed statistically significant correlation with survival or PSA response rates. However, the stage at the time of diagnosis was related to the PSA-DT. Clinically T3 and T4 patients had significantly lower PSA-DT (Table 2, Table 3).

The PSA response rate (PSA-R) was calculated as the ratio of the lowest PSA level under DX chemotherapy (PSAndx) to the last PSA level before DX chemotherapy (PSAa). (PSA-R $=$ PSAa/PSAndx)

The group of patients who had PSA-R $<50 \%$, had significantly lower survival rates $(\mathrm{p}=0.049)$. The median overall survival time was 21.37 months for these patients. On other hand, the $>50 \%$ PSA-R group had 33.23 months of median overall survival. These findings are shown in the Table 4.

\section{Discussion}

To predict the survival rates and response rates to chemotherapy for metastatic and castration resistant prostate cancer is not possible to our knowledge. We investigated our database to find out a prognostic factor that may be useful for predicting the prognosis of patients who are under docetaxel chemotherapy.

This may also be helpful to designate a cut-off value for making an extra move for therapy. The initial PSA levels differ a lot from patient to patient. This is because of the variable PSA expression of tumors and also the heterogeneity of the tumor cells [17].

One of the first studies about PSA-DT was published in 2001. At this study, a group considered to show a good prognosis (T1b or T2b, N0, M0, Gleason score $<7$, PSA $<15 \mathrm{ng} / \mathrm{ml}$ ) was evaluated and PSA-DT was 
Table 2. PSA-DT according to gleason scores.

\begin{tabular}{|c|c|c|c|c|c|}
\hline \multirow{2}{*}{ PSA-DT cutoff 75 days } & \multicolumn{3}{|c|}{ Gleason Score } & \multirow{2}{*}{ Total } & \multirow{2}{*}{$\mathrm{p}$} \\
\hline & $<7$ & 7 & $>7$ & & \\
\hline PSA-DT $\leq 75$ days & 7 & 18 & 11 & 36 & \\
\hline PSA-DT $>75$ days & 8 & 12 & 14 & 34 & 0.454 \\
\hline Total & 15 & 30 & 25 & 70 & \\
\hline \multirow{2}{*}{ PSA-DT cutoff 45 days } & \multicolumn{3}{|c|}{ Gleason Score } & \multirow{2}{*}{ Total } & \multirow{2}{*}{$\mathrm{p}$} \\
\hline & $<7$ & 7 & $>7$ & & \\
\hline PSA-DT $\leq 45$ days & 3 & 11 & 6 & 20 & \\
\hline PSA-DT $>45$ days & 12 & 19 & 19 & 50 & 0.414 \\
\hline Total & 15 & 30 & 25 & 70 & \\
\hline
\end{tabular}

Table 3. PSA-DT according to clinical stage.

\begin{tabular}{|c|c|c|c|c|}
\hline \multirow{2}{*}{ PSA-DT cutoff 75 days } & \multicolumn{2}{|c|}{ Clinical Stage } & \multirow{2}{*}{ Total } & \multirow{2}{*}{$\mathrm{p}$} \\
\hline & $\leq \mathrm{T} 2$ & $>\mathrm{T} 2$ & & \\
\hline PSA-DT $\leq 75$ days & 15 & 21 & 36 & \\
\hline PSA-DT > 75days & 20 & 14 & 34 & 0.116 \\
\hline Total & 35 & 35 & 70 & \\
\hline \multirow{2}{*}{ PSA-DT cutoff 45 days } & \multicolumn{2}{|c|}{ Clinical Stage } & \multirow{2}{*}{ Total } & \multirow{2}{*}{$\mathrm{p}$} \\
\hline & $\leq \mathrm{T} 2$ & $>\mathrm{T} 2$ & & \\
\hline PSA-DT $\leq 45$ days & 7 & 13 & 20 & \\
\hline PSA-DT >45days & 28 & 22 & 50 & 0.093 \\
\hline Total & 35 & 35 & 70 & \\
\hline
\end{tabular}

Table 4. PSA response rates to docetaxel chemotherapy.

\begin{tabular}{|c|c|c|}
\hline PSA-R & $\leq 50 \%$ & $>50 \%$ \\
\hline 1.year & $0.826 \pm 0.091$ & $0.72 \pm 0.060$ \\
\hline 2.year & $0.161 \pm 0.102$ & $0.581 \pm 0.100$ \\
\hline 5.year & $0.080 \pm 0.076$ & $0.090 \pm 0.082$ \\
\hline Median & $21.37 \pm 3.36$ & $33.23 \pm 3.67$ \\
\hline $95 \%$ GA & $14-27$ & $26-40$ \\
\hline Log Rank & \multicolumn{2}{|c|}{3.887} \\
\hline $\mathrm{p}$ & \multicolumn{2}{|c|}{0.049} \\
\hline
\end{tabular}

suggested to be a good predictor for survival rates [18]. Another study by Sengupta et al. showed that PSA-DT can be used as a prognostic factor for survival in patients receiving adjuvant hormonal therapy after radical prostatectomy [19].

The use of PSA-DT has been proposed as a value to classify the aggressiveness of prostate cancer [20]. Following this, many authors have demonstrated PSADT as a predictor of biochemical recurrence [14] [21]-[24].

To our own experience, some of the patients had a rising PSA after first dose of docetaxel. This does not mean a resistance to therapy or a clinical relapse or drug resistance in all cases. Still it makes the calculation of PSA-DT complicated. In addition, the PSA-DT may change for the same individual, at the different stages of the cancer [25] [26].

The previous studies generally focused on the correlation of PSADT for localized disease or biochemical relapse after curative treatments, but only a few studies have looked at PSA-DT for advanced disease.

Oudard and colleagues suggested that the PSA-DT over 45 days might be a valuable prognostic factor for survival for CRPC patients receiving docetaxel or mitoxantrone therapy [15]. Loberg et al. showed a significant 
decrease in the PSADT between the hormone naive prostate cancer state versus the HRPC state in both the groups of 249 patients reviewed in their study [27].

PSA-DT was suggested to be used as a predictor for biochemical recurrence, and a possible sign for systemic disease [14] [20] [28].

In 2008 a meta-analysis for all PSA kinetics was published. This article showed that $54 \%$ of all the studies suggested that PSA kinetics were useful for prostate cancer prognosis regardless of disease stage [29]. After this review, in 2014, Vickers and colleagues presented their commentary about PSA kinetics for making decisions about biopsy and initial treatment. They presented that recent studies, including analyses of cohorts from all the major randomized trials of localized prostate cancer, have failed to find any evidence that PSA kinetics are of benefit in this setting [30].

In 2015, Murray et al. presented their study about PSA kinetics and bone marrow micrometastasis to define local or systemic relapse in men with biochemical failure after radical prostatectomy for prostate cancer. The authors suggested that PSA doubling time of $<6$ months or a total serum PSA of $>2.5 \mathrm{ng} / \mathrm{ml}$ at the time of biochemical failure, the detection of bone marrow micrometastasis was significantly higher [31]. A recently published study from Chiaravalloti et al. showed that the use of PSA kinetics are helpful for selecting patients for PET/CT after radical prostatectomy [32]. Thomsen et al. presented their data on PSA kinetics for patients with localized prostate cancer. According to this the 13-year risk of mortality was associated with PSA-DT ( $\leq 3$ years: $62.0 \%$ versus $>3$ years: $16.3 \%, \mathrm{P}<0.0001$ ) [33].

In 2016 Uchio and colleagues suggested that a PSA-DT $\leq 2$ is useful to predict survival rates after radiation therapy, but on the other hand they couldn't find any significant predictive value for the patients who were treated by surgery first [34].

As a result, the main aim of the study was to evaluate if PSA doubling time was one of the prognostic factors for hormone refractory metastatic prostate cancer patients under docetaxel therapy. We found out no statistically significant proof for this hypothesis. In addition, we found that PSA response rate to chemotherapy is a very useful and valuable prognostic factor for this group of patients. If the patient had a $>50 \%$ PSA response to docetaxel therapy, regardless of the timing of the response, the median survival rates were significantly higher. We need more studies to find better prognostic factors for survival in patients receiving docetaxel chemotherapy for prostate cancer.

\section{References}

[1] Chodak, G. (2006) Prostate Cancer: Epidemiology, Screening, and Biomarkers. Reviews in Urology, 8, S3-S8.

[2] Andriole, G.L., Crawford, E.D., Grubb 3rd, R.L., Buys, S.S., Chia, D., Church, T.R., et al. (2012) Prostate Cancer Screening in the Randomized Prostate, Lung, Colorectal, and Ovarian Cancer Screening Trial: Mortality Results after 13 Years of Follow-Up. Journal of National Cancer Institute, 104, 125-132. http://dx.doi.org/10.1093/jnci/djr500

[3] Jhaveri, F.M., Klein, E.A., Kupelian, P.A., Zippe, C. and Levin, H.S. (1999) Declining Rates of Extracapsular Extension after Radical Prostatectomy: Evidence for Continued Stage Migration. Journal of Clinical Oncology, 17, 31673172.

[4] Mendhiratta, N., Lee, T., Prabhu, V., Llukani, E. and Lepor, H. (2015) 10-Year Mortality After Radical Prostatectomy for Localized Prostate Cancer in the Prostate-specific Antigen Screening Era. Urology, 86, 783-788. http://dx.doi.org/10.1016/j.urology.2015.05.034

[5] Campbell, M.F., Kavoussi, L.R. and Wein, A.J. (2012) Campbell-Walsh Urology. 10th Edition, Elsevier Saunders, Philadelphia, PA.

[6] Heidenreich, A., Bastian, P.J., Bellmunt, J., Bolla, M., Joniau, S., van der Kwast, T., et al. (2014) EAU Guidelines on Prostate Cancer. Part II: Treatment of Advanced, Relapsing, and Castration-Resistant Prostate Cancer. European Urology, 65, 467-479. http://dx.doi.org/10.1016/j.eururo.2013.11.002

[7] Attard, G., Parker, C., Eeles, R.A., Schröder, F., Tomlins, S.A., Tannock, I., et al. (2016) Prostate Cancer. The Lancet, 387, 70-82. http://dx.doi.org/10.1016/S0140-6736(14)61947-4

[8] Kratochwil, C., Giesel, F.L., Stefanova, M., Benesova, M., Bronzel, M., Afshar-Oromieh, A., et al. (2016) PSMATargeted Radionuclide Therapy of Metastatic Castration-Resistant Prostate Cancer with Lu-177 Labeled PSMA-617. Journal of Nuclear Medicine, 57, 1170-1176.

[9] Fizazi, K. (2013) Nonhormone Therapy for Metastatic Castration-Resistant Prostate Cancer: Chemotherapy, BoneTargeted Treatments, and Others. Am Soc Clin Oncol Educ Book.

http://dx.doi.org/10.1200/EdBook_AM.2013.33.e161 
[10] Gaya, J.M., Ahallal, Y., Sanchez-Salas, R., Barret, E., Rozet, F., Galiano, M., et al. (2013) Current, New and Novel Therapy for Castration-Resistant Prostate Cancer. Expert Review of Anticancer Therapy, 13, 819-827. http://dx.doi.org/10.1586/14737140.2013.811154

[11] Rescigno, P., Buonerba, C., Bellmunt, J., Sonpavde, G., De Placido, S. and Di Lorenzo, G. (2012) New Perspectives in the Therapy of Castration Resistant Prostate Cancer. Current Drug Targets, 13, 1676-1686. http://dx.doi.org/10.2174/138945012803529956

[12] Hwang, C. (2012) Overcoming Docetaxel Resistance in Prostate Cancer: A Perspective Review. Therapeutic Advances in Medical Oncology, 4, 329-340. http://dx.doi.org/10.1177/1758834012449685

[13] Oken, M.M., Creech, R.H., Tormey, D.C., Horton, J., Davis, T.E., McFadden, E.T., et al. (1982) Toxicity and Response Criteria of the Eastern Cooperative Oncology Group. American Journal of Clinical Oncology, 5, 649-655. http://dx.doi.org/10.1097/00000421-198212000-00014

[14] Pound, C.R., Partin, A.W., Eisenberger, M.A., Chan, D.W., Pearson, J.D. and Walsh, P.C. (1999) Natural History of Progression after PSA Elevation Following Radical Prostatectomy. JAMA, 281, 1591-1597.

http://dx.doi.org/10.1001/jama.281.17.1591

[15] Oudard, S., Banu, E., Scotte, F., Banu, A., Medioni, J., Beuzeboc, P., et al. (2007) Prostate-Specific Antigen Doubling Time before Onset of Chemotherapy as a Predictor of Survival for Hormone-Refractory Prostate Cancer Patients. Annals of Oncology, 18, 1828-1833. http://dx.doi.org/10.1093/annonc/mdm332

[16] Mehta, A., Stein, M., Goodin, S., Yao, S., Shih, J., Todd, M., et al. (2006) Pre-Treatment PSA Doubling Time (PSADT) Predicts Biochemical Response to Chemotherapy in Patients with Androgen Sensitive PSA Progression after Local Therapy. Journal of Clinical Oncology, 24, 14528.

[17] Partin, A.W., Pearson, J.D., Landis, P.K., Carter, H.B., Pound, C.R., Clemens, J.Q., et al. (1994) Evaluation of Serum Prostate-Specific Antigen Velocity after Radical Prostatectomy to Distinguish Local Recurrence from Distant Metastases. Urology, 43, 649-659. http://dx.doi.org/10.1016/0090-4295(94)90180-5

[18] Choo, R., DeBoer, G., Klotz, L., Danjoux, C., Morton, G.C., Rakovitch, E., et al. (2001) PSA Doubling Time of Prostate Carcinoma Managed with Watchful Observation Alone. International Journal of Radiation Oncology, Biology, Physics, 50, 615-620. http://dx.doi.org/10.1016/S0360-3016(01)01511-5

[19] Sengupta, S., Blute, M.L., Bagniewski, S.M., Myers, R.P., Bergstralh, E.J., Leibovich, B.C., et al. (2006) Increasing Prostate Specific Antigen Following Radical Prostatectomy and Adjuvant Hormonal Therapy: Doubling Time Predicts Survival. Journal of Urology, 175, 1684-1690. http://dx.doi.org/10.1016/s0022-5347(05)00978-X

[20] Bidart, J.M., Thuillier, F., Augereau, C., Chalas, J., Daver, A., Jacob, N., et al. (1999) Kinetics of Serum Tumor Marker Concentrations and Usefulness in Clinical Monitoring. Clinical Chemistry, 45, 1695-1707.

[21] Goluboff, E.T., Heitjan, D.F., DeVries, G.M., Katz, A.E., Benson, M.C. and Olsson, C.A. (1997) Pretreatment Prostate Specific Antigen Doubling Times: Use in Patients before Radical Prostatectomy. Journal of Urology, 158, 1876-1878. http://dx.doi.org/10.1016/s0022-5347(01)64154-5

[22] Hanks, G.E., Hanlon, A.L., Lee, W.R., Slivjak, A. and Schultheiss, T.E. (1996) Pretreatment Prostate-Specific Antigen Doubling Times: Clinical Utility of This Predictor of Prostate Cancer Behavior. International Journal of Radiation Oncology, Biology, Physics, 34, 549-553. http://dx.doi.org/10.1016/0360-3016(95)02154-X

[23] Laufer, M., Pound, C.R., Carducci, M.A. and Eisenberger, M.A. (2000) Management of Patients with Rising ProstateSpecific Antigen after Radical Prostatectomy. Urology, 55, 309-315. http://dx.doi.org/10.1016/S0090-4295(99)00465-3

[24] Stephenson, A.J., Aprikian, A.G., Souhami, L., Behlouli, H., Jacobson, A.I., Begin, L.R., et al. (2002) Utility of PSA Doubling Time in Follow-Up of Untreated Patients with Localized Prostate Cancer. Urology, 59, 652-656. http://dx.doi.org/10.1016/S0090-4295(02)01526-1

[25] Duchesne, G.M., Millar, J.L., Moraga, V., Rosenthal, M., Royce, P. and Snow, R. (2003) What to Do for Prostate Cancer Patients with a Rising PSA?-A Survey of Australian Practice. International Journal of Radiation Oncology, Biology, Physics, 55, 986-991. http://dx.doi.org/10.1016/S0360-3016(02)04213-X

[26] Scher, H.I. and Heller, G. (2000) Clinical States in Prostate Cancer: Toward a Dynamic Model of Disease Progression. Urology, 55, 323-327. http://dx.doi.org/10.1016/S0090-4295(99)00471-9

[27] Loberg, R.D., Fielhauer, J.R., Pienta, B.A., Dresden, S., Christmas, P., Kalikin, L.M., et al. (2003) Prostate-Specific Antigen Doubling Time and Survival in Patients with Advanced Metastatic Prostate Cancer. Urology, 62, 128-133. http://dx.doi.org/10.1016/j.urology.2003.10.026

[28] Hanks, G.E., Hanlon, A.L., Lee, W.R., Slivjak, A. and Schultheiss, T.E. (1996) Pretreatment Prostate-Specific Antigen Doubling Times: Clinical Utility of This Predictor of Prostate Cancer Behavior. International Journal of Radiation Oncology, Biology, Physics, 34, 549-553. http://dx.doi.org/10.1016/0360-3016(95)02154-X 
[29] Vickers, A.J., Savage, C., O’Brien, M.F. and Lilja, H. (2009) Systematic Review of Pretreatment Prostate-Specific Antigen Velocity and Doubling Time as Predictors for Prostate Cancer. Journal of Clinical Oncology, 27, 398-403. http://dx.doi.org/10.1200/JCO.2008.18.1685

[30] Vickers, A.J., Thompson, I.M., Klein, E., Carroll, P.R. and Scardino, P.T. (2014) A Commentary on PSA Velocity and Doubling Time for Clinical Decisions in Prostate Cancer. Urology, 83, 592-598. http://dx.doi.org/10.1016/j.urology.2013.09.075

[31] Murray, N.P., Reyes, E., Fuentealba, C., Orellana, N. and Jacob, O. (2015) Comparison between Use of PSA Kinetics and Bone Marrow Micrometastasis to Define Local or Systemic Relapse in Men with Biochemical Failure after Radical Prostatectomy for Prostate Cancer. Asian Pacific Organization for Cancer Prevention, 16, 8387-8390. http://dx.doi.org/10.7314/APJCP.2015.16.18.8387

[32] Chiaravalloti, A., Di Biagio, D., Tavolozza, M., Calabria, F. and Schillaci, O. (2016) PET/CT with (18)F-Choline after Radical Prostatectomy in Patients with PSA $\leq 2 \mathrm{ng} / \mathrm{ml}$. Can PSA velocity and PSA Doubling Time Help in Patient Selection? European Journal of Nuclear Medicine and Molecular Imaging, 43, 1418-1424. http://dx.doi.org/10.1007/s00259-015-3306-0

[33] Thomsen, F.B., Brasso, K., Berg, K.D., Gerds, T.A., Johansson, J.E., Angelsen, A., et al. (2016) Association between PSA Kinetics and Cancer-Specific Mortality in Patients with Localised Prostate Cancer: Analysis of the Placebo Arm of the SPCG-6 Study. Annals of Oncology, 27, 460-466. http://dx.doi.org/10.1093/annonc/mdv607

[34] Uchio, E., Aslan, M., Ko, J., Wells, C.K., Radhakrishnan, K. and Concato, J. (2016) Velocity and Doubling Time of Prostate-Specific Antigen: Mathematics Can Matter. Journal of Investigative Medicine, 64, 400-404. http://dx.doi.org/10.1136/jim-2015-000008

\section{Submit or recommend next manuscript to SCIRP and we will provide best service for you:}

Accepting pre-submission inquiries through Email, Facebook, LinkedIn, Twitter, etc. A wide selection of journals (inclusive of 9 subjects, more than 200 journals)

Providing 24-hour high-quality service

User-friendly online submission system

Fair and swift peer-review system

Efficient typesetting and proofreading procedure

Display of the result of downloads and visits, as well as the number of cited articles

Maximum dissemination of your research work

Submit your manuscript at: http://papersubmission.scirp.org/ 